\title{
Perbandingan Tramadol dengan Lidokain untuk Mengurangi Derajat Nyeri Penyuntikan Propofol
}

\author{
Oka Endarto, Ruli Herman Sitanggang, Budiana Rismawan \\ Departemen Anestesiologi dan Terapi Intensif \\ Fakultas Kedokteran Universitas Padjadjaran/RSUP Dr. Hasan Sadikin Bandung
}

\begin{abstract}
Abstrak
Propofol adalah obat anestesi intravena yang sering digunakan untuk tidakan medis karena memiliki onset dan durasi cepat. Nyeri saat penyuntikan propofol merupakan permasalahan yang sering dikeluhkan pasien dan berbagai metode telah dilakukan untuk mengurangi derajat nyeri penyuntikan propofol, namun masih didapatkan nyeri. Lidokain menjadi standar emas untuk mengurangi derajat nyeri penyuntikan propofol, tetapi masih memiliki efek samping seperti penekanan fungsi jantung sehingga dipilih tramadol yang tidak menekan fungsi jantung dan dapat menurunkan kebutuhan obat antinyeri selama maupun setelah operasi. Penelitian ini bertujuan membandingkan pemberian tramadol dengan lidokain untuk mengurangi derajat nyeri penyuntikan propofol. Metode penelitian menggunakan uji klinis acak buta tunggal terhadap 60 pasien yang menjalani operasi elektif. Pasien dibagi menjadi 2 kelompok, yaitu perlakuan tramadol (kelompok T) dan perlakuan lidokain (kelompok L) disertai pembendungan vena permukaan menggunakan tourniquet, kemudian diberikan tramadol atau lidokain. Setelah 1 menit tourniquet dilepaskan dan diikuti dengan penyuntikan $1 / 4$ dosis total propofol untuk induksi selama 5 detik, lalu dilakukan penilaian derajat nyeri menggunakan verbal rating score. Hasil penelitian menunjukkan penurunan derajat nyeri penyuntikan propofol pada kedua kelompok dan tidak terdapat perbedaan bermakna ( $p>0,05)$, namun melalui uji statistik dengan tingkat kepercayaan sebesar 95\% menyatakan tramadol memiliki risiko relatif kemungkinan terjadi nyeri ringan lebih kecil dibanding dengan lidokain menurunkan derajat nyeri penyuntikan propofol. Simpulan, Tramadol memiliki kekuatan yang sama dengan lidokain dalam menurunkan derajat nyeri penyuntikan propofol.
\end{abstract}

Kata kunci: Lidokain, nyeri, propofol, tramadol, verbal rating score

\section{Comparison between Tramadol and Lidocaine in Reducing Pain Triggered by Propofol Injection}

\begin{abstract}
Propofol is a commonly used intravenous anesthetics in medical procedure. Pain during propofol injection is a commonly reported adverse effect of this injection. Various methods have been proposed to reduce pain but often fail. Lidocaine is the gold standard for reducing pain during injection of propofol but has a suppressive effect on the heart. Tramadol does not have a suppressive effect and reduce the need for antipain medication during and after surgery thereforeTramadol is chosen for this purpose. This study aimed to compare the administration of tramadol and lidocaine to reduce the level of pain during propofol injection. This was a single blind randomized clinical trial on 60 patients underwent elective surgery. Patients were divided into 2 groups: the first group received tramadol (group T) and the second group received lidocaine (group L). Tourniquet was used on each patient before injection of tramadol or lidocaine was given and it was removed after 1 minute. Pain severity was assessed 5 seconds after propofol injection using the verbal rating score. This study discovered that pain during propofol injection was reduced with the use of tramadol and lidocaine without significant difference between the two $(p>0.05)$. However, tramadol has a lower probability of mild pain than lidocaine with interval confidence $95 \%$. In conclusion, tramadol has the same potential as lidocaine in reducing the level of pain related to propofol injection
\end{abstract}

Key words: Lidocaine, pain, propofol, tramadol, verbal rating score

Korespondensi: Oka Endarto. dr, Departemen Anestesiologi dan Terapi Intensif Fakultas Kedokteran Universitas Padjadjaran/RSUP Dr. Hasan Sadikin Bandung, Jl. Pasteur No. 38 Bandung 40161, Tlpn (022) 203-8285, Email okariseup@gmail.com 


\section{Pendahuluan}

Propofol merupakan hipnotik/sedatif yang sering digunakan untuk tindakan pembiusan baik di dalam maupun di luar kamar operasi. ${ }^{1}$ Induksi anestesi, pemeliharaan anestesi, premedikasi, sedasi pasien di Intensive Care Unit (ICU), serta sedasi saat tindakan medis merupakan beberapa contoh penggunaan propofol. ${ }^{1}$ Propofol banyak dijadikan pilihan karena onset kerja yang cepat dan durasi yang pendek sehingga waktu pulih sadar, kembalinya refleks protektif, kognitif, dan fungsi psikomotor dapat berlangsung cepat. ${ }^{1}$

Nyeri yang timbul akibat penyuntikan propofol menjadi masalah dengan angka kejadian yang cukup tinggi, yaitu 28\% sampai $90 \%{ }^{2}$ Nyeri penyuntikan propofol terjadi karena iritasi dinding pembuluh darah vena yang mengandung saraf sensoris akibat kontak langsung dengan fraksi bebas propofol. ${ }^{2}$ Dampak dari nyeri penyuntikan propofol menyebabkan rasa tidak nyaman bagi pasien sehingga menurunkan kualitas pelayanan anestesi. $^{2}$

Angka kejadian nyeri saat penyuntikan propofol yang tinggi dapat dikurangi dengan beberapa cara danteknikseperti mendinginkan atau menghangatkan propofol, penyuntikan pada vena-vena besar, mengatur kecepatan penyuntikan, mengubah emulsi propofol menjadi $50 \%$ medium chain triglyceride (MCT) atau 50\% long chain triglyceride (LCT), pemberian obat seperti lidokain, ketamin, opioid, metoklopramid, ondansetron, steroid, tiopental, dan efedrin sebelum penyuntikan propofol. $^{3}$

Penggunaan lidokain untuk mengurangi nyeri diakibatkan penyuntikan propofol pada beberapa penelitian dilaksanakan dengan mencampur lidokain dan propofol, namun cara ini kurang efektif karena masih didapatkan kejadian nyeri penyuntikan dan terdapat efek samping pemberian lidokain. ${ }^{3}$

Penelitian lain mempergunakan teknik pemberian lidokain terlebih dahulu secara intravena disertai bendungan vena permukaan menggunakan tourniquet sebelum pemberian propofol dan didapatkan pengurangan nyeri yang lebih baik. ${ }^{3}$ Lidokain sebagai standar emas obat anestesi lokal pada saraf tepi mampu menghambat penjalaran impuls nyeri melalui penutupan pintu natrium pada perlakuan pembendungan vena permukaan menggunakan tourniquet sehingga berakibat tidak terjadi aksi potensial penjalaran impuls nyeri pada saraf tepi yang berada di sekitar vena permukaan tangan. ${ }^{4}$

Peneliti berupaya mencari obat lain untuk mengurangi nyeri oleh penyuntikan propofol dengan mempergunakan tramadol, hal ini dikarenakan tramadol bekerja pada reseptor opioid yang berada pada membran saraf pusat dan tepi serta memiliki mekanisme yang sama dengan obat anestesi lokal melalui hambatan pintu natrium sehingga tidak terjadi penjalaran nyeri. ${ }^{5}$ Keunggulan tramadol dibanding dengan lidokain untuk mengurangi derajat nyeri penyuntikan propofol adalah kebutuhan obat antinyeri selama dan setelah operasi yang lebih rendah serta tidak menekan fungsi jantung. ${ }^{5}$

Tujuan penelitian adalah membandingkan tramadol $50 \mathrm{mg}$ i.v dengan lidokain 2\% $40 \mathrm{mg}$ i.v dalam mengurangi derajat nyeri penyuntikan propofol.

\section{Subjek dan Metode}

Penelitian ini merupakan uji klinis yang dilakukan dengan cara uji acak terkontrol buta tunggal (single blind randomized control trial) dengan teknik pengambilan data melalui pengamatan langsung pada pasien. Subjek penelitian adalah semua pasien yang menjalani operasi elektif di RSUP Dr. Hasan Sadikin Bandung pada bulan Agustus 2018 hingga Oktober 2018. Kriteria inklusi pada penelitian ini adalah pasien yang dilakukan teknik anestesi umum, pasien dengan indek massa tubuh (IMT) $18-30 \mathrm{~kg} / \mathrm{m}^{2}$, status fisik berdasarkan American Society of Anesthesiologist (ASA) kelas I dan II, dan usia 18 sampai 60 tahun. Kriteria eksklusi tidak ditemukan pada penelitian ini.

Penentuan besar sampel berdasar formula rumus untuk menguji perbedaan dua proporsi dengan taraf signifikansi $\alpha=5 \%(Z \alpha=1,65$; 
uji satu pihak) power test $80 \%(\mathrm{Z} \beta=0,84)$ didapatkan jumlah sampel tiap-tiap kelompok sebanyak 30 orang. Penelitian ini dilakukan setelah mendapatkan persetujuan dari Komite Etik Penelitian Kesehatan Fakultas Kedokteran Universitas Padjadjaran/RSUP Dr. Hasan Sadikin Bandung No: LB.04.01/A05/EC/236/ VIII/2018.

Subjek penelitian yang sudah diberikan penjelasan kemudian mengerti dan setuju untuk terlibat dalam penelitian dibagi dalam dua kelompok, yaitu kelompok perlakuan tramadol (kelompok T) serta kelompok perlakuan lidokain (kelompok L) yang masing masing terdiri dari 30 orang. Teknik pengambilan sampel penelitian dilakukan dengan teknik consecutive sampling dan subjek dialokasikan ke dalam salah satu kelompok mempergunakan blok permutasi. ${ }^{5}$

Subjek dipasang jalur intravena dengan jarum 20 gauge pada vena di dorsum manus (pemasangan dapat dilakukan saat pasien masih di ruangan atau setelah di kamar operasi). Setelah pasien masuk ke kamar operasi atau ruang tindakan medis dilakukan pemasangan alat pantau EKG, tensimeter, dan saturasi oksigen. ${ }^{5}$

Tourniquet di pasang pada lengan atas (daerah brakialis) bagian tangan yang sudah terpasang jalur i.v dengan tekanan 70 mmHg yang merupakan tekanan minimal untuk membendung vena permukaan pada kelompok perlakuan $\mathrm{T}$ (tramadol) dan $\mathrm{L}$ (lidokain), kemudian diberikan tramadol 50 mg (tramadol $1 \mathrm{~mL}+$ akuabides $1 \mathrm{~mL}$ ) i.v pada kelompok perlakuan $\mathrm{T}$ (tramadol) dan lidokain $2 \% 40 \mathrm{mg}(2 \mathrm{~mL})$ i.v pada kelompok perlakuan L (lidokain), setelah 1 menit tourniquet dilepas dan dilakukan penyuntikan $1 / 4$ dosis total propofol untuk induksi ( $2 \mathrm{mg} / \mathrm{kgBB}$ i.v) selama 5 detik, kemudian tiap-tiap subjek penelitian dinilai derajat nyeri dengan verbal rating scale (VRS) sebelum onset propofol tercapai. ${ }^{6}$

Data dianalisis secara deskriptif dan analitis. Analisis secara deskriptif dengan menyajikan ukuran statistikjumlah, persentase

Tabel 1 Karakteristik Subjek Penelitian

\begin{tabular}{|c|c|c|c|}
\hline \multirow[b]{2}{*}{ Karakteristik } & \multicolumn{2}{|c|}{ Perlakuan } & \multirow[b]{2}{*}{ Nilai $\mathbf{p}^{*}$} \\
\hline & $\begin{array}{c}\text { Tramadol } 50 \mathrm{mg} \\
(\mathrm{n}=30)\end{array}$ & $\begin{array}{c}\text { Lidokain } 2 \% 40 \mathrm{mg} \\
(\mathrm{n}=30)\end{array}$ & \\
\hline \multicolumn{4}{|l|}{ Jenis kelamin } \\
\hline Laki-laki (n) & 5 & 9 & 0,222 \\
\hline Perempuan (n) & 25 & 21 & \\
\hline \multicolumn{4}{|l|}{ Usia (tahun) } \\
\hline Rerata (SB) & $39,5(11,9)$ & $41,0(12,6)$ & 0,610 \\
\hline Rentang & $17-57$ & $20-59$ & \\
\hline \multicolumn{4}{|l|}{ Berat badan $(\mathrm{kg})$} \\
\hline Rerata (SB) & $60,5(9,0)$ & $58,5(7,7)$ & 0,368 \\
\hline Rentang & $46-83$ & $47-78$ & \\
\hline \multicolumn{4}{|l|}{ Tinggi badan $(\mathrm{cm})$} \\
\hline Rerata (SB) & $157,8(9,1)$ & $159,6(6,7)$ & 0,397 \\
\hline Rentang & $145-178$ & $145-171$ & \\
\hline \multicolumn{4}{|l|}{ IMT $\left(\mathrm{kg} / \mathrm{m}^{2}\right)$} \\
\hline Rerata (SB) & $24,1(2,7)$ & $23,0(2,5)$ & 0,076 \\
\hline Rentang & $19,5-29,1$ & $19,0-28,9$ & \\
\hline \multicolumn{4}{|l|}{ ASA } \\
\hline I & 19 & 17 & 0,598 \\
\hline II & 11 & 13 & \\
\hline
\end{tabular}

Keterangan: *) usia dan tinggi badan dengan uji $T$, berat badan dan IMT dengan Uji Mann-Whitney, jenis kelamin dan ASA dengan chi-kuadrat dinyatakan bermakna bila $\mathrm{p}<0,05$ 
Tabel 2 Penilaian Skala Nyeri pada Kelompok Perlakuan

\begin{tabular}{|c|c|c|c|c|}
\hline \multirow{2}{*}{ VRS } & \multicolumn{2}{|c|}{ Kelompok Perlakuan } & \multicolumn{2}{|c|}{ Nilai $p^{*}$} \\
\hline & Tramadol $50 \mathrm{mg}$ & Lidokain $2 \% 40 \mathrm{mg}$ & $\mathbf{R R}$ & IK \\
\hline 0 & 27 & 23 & \multirow{4}{*}{0,166} & \multirow{4}{*}{$0,4295 \%$} \\
\hline 1 & 3 & 7 & & \\
\hline 2 & 0 & 0 & & \\
\hline 3 & 0 & 0 & & \\
\hline
\end{tabular}

Keterangan: *) berdasar uji chi-kuadrat; bermakna jika p<0,05, Risiko relatif (RR), Interval kepercayaan (IK)

untuk ukuran kategori, sedangkan untuk data numerik dengan menyajikan nilai rerata dan simpang baku, atau nilai median dengan rentang jika data tidak berdistribusi normal. Perhitungan data secara analitik menggunakan uji $T$ untuk membandingkan perbedaan dua rerata data berdistribusi normal, sedangkan untuk data dengan distribusi tidak normal digunakan Uji Mann-Whitney, uji chi-kuadrat digunakan untuk membandingkan perbedaan dua proposi pada data kategori sedangkan untuk mengetahui besar risiko dihitung risiko relatif dengan tingkat kepercayaan 95\%.

\section{Hasil}

Penelitian dilakukan terhadap 60 pasien yang telah menjalani operasi elektif dan memenuhi kriteria inklusi. Tidak ada data yang dieksklusikan. Karakteristik subjek penelitian antara kedua kelompok berdasar jenis kelamin, usia, berat badan, tinggi badan, IMT, dan ASA yang telah dihitung menggunakan uji $T$, Uji Mann-Whitney dan uji Chi-kuadrat tidak ada perbedaan bermakna ( $p>0,05$; Tabel 1 ).

Derajat nyeri penyuntikan propofol skala nyeri 0 (tidak nyeri) didapatkan lebih banyak pada kelompok tramadol (27 subjek) dibanding dengan kelompok lidokain (23 subjek), sedangkan skala nyeri 1 (nyeri ringan) didapatkan lebih sedikit pada kelompok tramadol (3 subjek) dibanding dengan kelompok lidokain (7 subjek). Nyeri sedang dan berat pada penelitian ini tidak didapatkan. Risiko relatif untuk kemungkinan terjadi nyeri ringan pada kelompok perlakuan tramadol dibanding dengan lidokain dengan indeks kepercayaan 95\% didapatkan nilai 0,42.
Derajat nyeri penyuntikan propofol pada kedua kelompok secara statistik tidak terdapat perbedaan bermakna ( $p>0,05$; Tabel 2)

\section{Pembahasan}

Propofol adalah obat hipnotik/sedatif yang sering digunakan untuk tindakan pembiusan, namun menimbulkan nyeri penyuntikan yang mengakibatkan ketidaknyamanan pasien. ${ }^{7}$

Pada penelitian ini didapatkan jumlah sampel sebanyak 60 pasien dengan karakteristik subjek penelitian menurut jenis kelamin, usia, tinggi badan, berat badan, indeks massa tubuh (IMT), dan status fisik anestesi berdasarkan American Society Anesthesiology (ASA) yang telah dihitung menggunakan uji $T$, Uji Mann-Whitney dan uji chi-kuadrat tidak terdapat perbedaan bermakna $(p>0,05)$ sehingga karakteristik pasien kedua kelompok dinyatakan homogen dan layak diperbandingkan.

Penilaian nyeri peneltian ini digunakan verbal rating scale (VRS) karena lebih mudah dinilai sebelum onset propofol tercapai. ${ }^{6}$ Hasil penelitian ini didapatkan derajat nyeri penyuntikan propofol antara kedua kelompok perlakuan tidak berbeda bermakna ( $p>0,05$; Tabel 2).

Mekanisme nyeri penyuntikan propofol berhubungan dengan iritasi langsung obat sehingga terjadi stimulasi reseptor vena nosisepsi atau ujung saraf bebas yang berada di sekitar vena. ${ }^{7}$ Nyeri penyuntikan propofol berhubungan dengan kosentrasi fraksi bebas propofol dalam lipid dan 90\% fase air karena bahan dasar propofol adalah emulsi minyak dalam air yang mengandung kedelai, gliserol, 
danlesitin teluryang dapatmenimbulkan iritasi pada mukosa dinding vena. ${ }^{7}$ Rangsangan nyeri akan ditangkap oleh serabut saraf sensoris bermielin tipe A-delta dan tipe $\mathrm{C}$, kemudian oleh poly-mechano reseptor rangsangan nyeri diubah menjadi impuls listrik, proses tersebut disebut fase transduksi. ${ }^{8}$ Proses selanjutnya transmisi, yaitu penjalaran aktivitas listrik pada membran sel saraf dengan melibatkan aktivitas pintu natrium, ketika pintu natrium terbuka maka ion natrium masuk ke dalam sel saraf dan terjadi aksi potensial dari impuls listrik sehingga rangsangan nyeri akan diteruskan ke pusat penghantar nyeri yang lebih tinggi di saraf pusat melalui suatu proses modulasi. ${ }^{8}$ Proses modulasi merupakan modifikasi terhadap stimulus nyeri. Modifikasi ini dapat terjadi peningkatan atau penghambatan terhadap impuls nyeri sepanjang proses transmisi hingga ke korteks serebri untuk dipersepsikan sebagai suatu nyeri. ${ }^{9}$ Tidak semua impuls nyeri akan diteruskan ke tingkat penghantar nyeri yang lebih tinggi, namun akan terjadi proses interaksi antara impuls yang diterima dan penghambat endogen (hormon endorfin, mediator anti-inflamasi) atau eksogen (opioid saraf tepi, mediator proinflamasi). ${ }^{9}$

Tramadol tersebut memiliki kemampuan menghambat aktivasi pintu natrium sehingga tidak terjadi penjalaran impuls listrik pada fase transmisi. ${ }^{10}$ Tramadol juga dapat menghambat nyeri pada proses modulasi melalui aktivasi reseptor opioid saraf tepi. Hal ini dibuktikan melalui suatu penelitian pemberian tramadol untuk memblok saraf sciatic tikus yang diberikan naloxone (antiopioid), tetapi masih didapatkan efek nyeri akibat ikatan dengan reseptor nonopiod pada saraf tepi. ${ }^{11}$

Perakuan pemberian tramadol $50 \mathrm{mg}$ secara i.v. disertai perlakuan bendungan vena menggunakan tourniquet dengan tekanan 70 mmHg selama 1 menit menyebabkan tramadol berdifusi melalui dinding vena yang permeable untuk berikatan dengan saraf sensoris penghantar nyeri di sekitar vena permukaan untuk bekerja menghambat nyeri pada proses transmisi melalui penutupan pintu natrium. ${ }^{12}$ Akibat perlakuan tourniquet menyebabkan sedikit obat tramadol yang berikatan dengan plasma dalam darah untuk beredar ke seluruh tubuh sehingga kemampuan tramadol dalam berikatan dengan reseptor opioid baik di saraf pusat atau tepi pada proses modulasi juga tidak terlalu kuat sehingga lewat beberapa penelitian tentang perbandingan tramadol dengan lidokain dalam menghambat nyeri pada saraf tepi tidak terdapat perbedaan yang bermakna jika dihitung secara statistik. ${ }^{13,14}$

Hal ini tidak berbeda dengan beberapa penelitian tentang perbandingan kekuatan tramadol dengan lidokain dalam mengurangi nyeri penyuntikan propofol, namun tramadol memiliki kelebihan jika dibanding dengan lidokain, yaitu mampu menurunkan kebutuhan obat antinyeri selama dan setelah operasi serta tidak menekan fungsi jantung. ${ }^{15}$

Lidokain bekerja menghambat nyeri melalui penutupan pintu natrium pada proses transmini, pada penelitian ini digunakan dosis equiuqlen lidokain $2 \% 40 \mathrm{mg}$ i.v. dan tramadol $50 \mathrm{mg}$ i.v. yang setara dengan dosis $1 \mathrm{mg} / \mathrm{kg} .{ }^{15}$ Lidokain merupakan standar emas obat anestesi lokal yang berasal dari golongan amida yang tidak menimbulkan reaksi alergi dengan tingkat keamanan yang cukup..$^{15}$ Obat anestesi lokal bekerja menghambat penjalaran impuls nyeri dengan cara menutup pintu natrium terutama pada preoses transmisi, namun ada juga obat anestesi lokal yang menghambat nyeri pada proses modulasi misalnya jika diberikan melalui teknik spinal atau epidural. ${ }^{16}$

Beberapa penelitian yang membandingkan kekuatan tramadol dengan obat anestesi lokal dalam menurunkan derajat nyeri pada saraf tepi tidak didapat perbedaan bermakna, misalnya pada penelitian kekuatan tramadol pada saraf tepi melalui cara penyuntikan subkutan pada pasien operasi inguinal hernioraphy menyatakan bahwa tramadol meskipun bekerja pada reseptor opioid saraf tepi dan menghambat pintu natrium, tetapi kekuatan dalam menurunkan nyeri tidak terdapat perbedaan bermakna bila dibanding dengan obat anestesi lokal, namun tramadol memiliki kelebihan seperti menurunkan kejadian mual muntah dan nyeri setelah 
operasi. ${ }^{16}$

Tramadol yang diberikan secara infiltrasi lokal pada mukosa mulut untuk operasi bedah mulut memiliki onset, durasi, dan kekuatan menghambat nyeri yang sama dengan lidokain yang diberikan secara infiltrasi pada mukosa mulut. ${ }^{16}$ Hasil penelitian juga menyatakan bahwa tramadol dapat digunakan sebagai pengganti lidokain karena memiliki efek anestesi dengan tingkat keamanan yang dapat digunakan untuk operasi. ${ }^{17}$

Penelitian tentang perbandingan kekuatan tramadol dengan lidokain dalam mengurangi nyeri pada saraf tepi didapatkan bahwa tidak terdapat perbedaan bermakna $(p>0,05) \cdot{ }^{18}$

Uji statistik chi-kuadrat menyatakan hasil tidak terdapat perbedaan bermakna $(p>0,05)$ antara tramadol $50 \mathrm{mg}$ i.v. dengan lidokain 2\% $40 \mathrm{mg}$ i.v. dalam menurunkan derajat nyeri penyuntikan propofol namun dalam penelitian ini didapatkan risiko relatif (RR) 0,42.

Risiko relatif penelitian ini didapatkan kurang dari $1(R R=0,42)$ yang berarti bahwa penyuntikan propofol yang dikombinasikan tramadol memiliki risiko kemungkinan terjadi nyeri ringan lebih kecil dibanding dengan injeksi propofol yang dikombinasikan dengan lidokain. ${ }^{19}$ Risiko nyeri yang lebih kecil ini mungkin berhubungan dengan mekanisme kerja tramadol yang memiliki kekuatan ganda yang dapat menghambat nyeri dengan menghambat pintu natrium dan berikatan dengan reseptor opioid saraf tepi, sedangkan lidokain hanya bekerja menghambat pintu natrium. ${ }^{20}$

Keterbatasn penelitian ini adalah alat ukur nyeri masih bersifat subjektif yang dipengaruhi oleh faktor-faktor pengalaman, emosional, kecemasan, tingkat pendidikan, dan ambang batas nyeri tiap individu yang berbeda sehingga hasil persepsi tiap individu dengan rangsangan nyeri yang sama dapat menghasilkan skala nyeri yang berbeda. Tingkat pendidikan pasien tidak dicantumkan karena dengan perbedaan tingkat pendidikan seseorang dalam penelitian ini mampu memengaruhi persepsi nyeri pada pasien. Perbedaan dan pengalaman tiap individu yang berbeda terhadap nyeri dapat memengaruhi hasil penilaian skala ukur nyeri dan alat syringe pump yang dapat digunakan untuk memberian propofol dengan kecepatan $1 \mathrm{~mL} /$ detik tidak ada di RSUP Dr Hasan Sadikin Bandung.

\section{Simpulan}

Tramadol $50 \mathrm{mg}$ i.v. memiliki kekuatan yang sama dengan lidokain 2\% $40 \mathrm{mg}$ i.v. dalam menurunkan derajat nyeri penyuntikan propofol di RSUP Dr. Hasan Sadikin Bandung. Tramadol $50 \mathrm{mg}$ i.v. masih memiliki risiko relatif kemungkinan terjadi nyeri ringan lebih kecil daripada lidokain $2 \% 40 \mathrm{mg}$ i.v. dalam menurunkan derajat nyeri penyuntikan propofol di RSUP Dr. Hasan Sadikin Bandung.

\section{Daftar Pustaka}

1. Sunny A, Vererabhadriah $\mathrm{T}$, Trivikam S. Comparison of pretreatment with lignocaine and ondansetron for pain on injection of propofol during Induction anesthesia. Inter J Anesth. 2013;32:1-4.

2. Sim JY, Lee SH, Park DY, Jung JA, Ki $\mathrm{KH}$, Lee DH, dkk. Pain on injection with microemulsion propofol. BJCP. 2009;67(3):316-25.

3. Walker BJ, Neal JM, Mulroy MF, Humsi JA, Bittner RC, McDonal SB. Lidocaine pretreatment with torniquet versus lidocaine-propofol admixture fo attenuating propofol injection pain. Reg Anesth Pain Med. 2011;36(1):41-5.

4. Syah SH, Buchari RH, Navqi SS. Efficacy of intravenous tramadol in reduction of propofol induction pain. Anesth Pain Intens Care J. 2016;20(2):150-3.

5. Bashir A, Abbas Z, Farhat S, Ahmed M, Tandon VR, Singh Z, dkk. A prospective randomized open labelled placebo controlled study comparing intravenous lignocaine and tramadol reducing the incidence and severity of pain on propofol injection. JK Sci. 2011;13(3):119-23.

6. Hjermstad MJ, Peter M, Frayer, Haugen DF, Caraceni A, Geofefery WH, dkk. Study comparing numerical rating scales, verbal rating scales, and visual analogue scale 
for assesment of pain intensity in adults: a systematic literature review. J Pain Symtom Manag. 2011;6:1073-93.

7. Biswal S, Moningi S, Rachmahardan G. Effect of intravenous tramadol, acemtaminophen in attenuating pain on propofol injection. comparison with lignocaine: a randomized double blind control study. Kanataka Anesthesiol. 2015;1:118-22

8. Hiller S. Non barbiturat intravenous anesthetic drug. Dalam: Stoelting RK, penyunting. Pharmacology and physiology in anaesthetic practice. Edisi ke-5. Philadelphia: Lippincott Williams and Wilkins; 2015. hlm. 155-63.

9. Richard RW, Vrooman BM. Chronic pain management. Dalam: Morgan G, penyunting. Morgan and Mikhail's clinical anesthesiology. Edisi ke-5. Philadelphia: McGraw-Hill; 2013. hlm. 1023-37.

10. Hiller S. Opioid agonist and antagonist. Dalam: Stoelting RK, penyunting. Pharmacology and physiology in Anaesthetic Practice. Edisi ke-5. Philadelphia: Lippincott Williams and Wilkins; 2015. hlm. 117.

11. Jendi KS, Syed AM, Badal S, Daiphode A, Chougule SS, Shaikh SA, dkk. Comparison of local aneshtetic efficacy of tramadol versus lignocaine for extraction of tooth under supraperiosteal infiltration. J Maxillofac Org Surg. 2018;3:1-6.

12. Ege B, Cakisir M, Haideri YA, Ege M, Gurgomus M. Comparison of local aneshtetic efficiency of tramadol hydrocloride and lidocaine hydrochloride. J Oral Maxillofac Surg. 2017;10:1-8.

13. Jalota L, Kalira V, George E, Shi YY, Radke
O, Pace N. Prevention of pain on injection propofol: Systematic review and metaanalysis. BMJ. 2011;342:1-18.

14. Stephen M, Macres, Peter G, Scott FM. Managemen of acute and cronic pain. Dalam: Barash PG, penyunting Clinical anesthesia fundamental. Philadelphia: Lippincott Williams and Wilkins; 2013. hlm. 699-718.

15. Madan HK, Sigh R, Sodhi GS. Comparison of intravenous lignocaine, tramadol, ketorolac for attentuation of propofol injection pain. Clin Diagn Res. 2016;10(7):5-8.

16. Santos TOD, Estrela TG, Azevedo VL, Oliveira OE, Junior GO, Figueiredo GS. Intravenous and subcutaneus tramadol for inguinal herniorraphy: comparative study. Rev Bras Anestesiol J. 2010;60(5):522-7.

17. Richad RW, Vrooman BM. Local anesthethics. Dalam: Morgan G, penyunting. Morgan and Mikhail's clinical anesthesiology. Edisi ke-5. Philadelphia: McGraw-Hill; 2013. hlm. 263-76.

18. Vahabi S, Heidari M, Ahmadinejad M, Akhlaghi J, Birjanji M. Comparison of local aneshtetic effects of tramadol versus lidocaine used subcutaneously in minor surgeries with local anesthesia. MEJ Anesth. 2011;1:9-13.

19. Hiller S. Local anesthethics. Dalam: Stoelting RK, penyuting. Pharmacology and Physiology in anaesthetic practice. Edisi ke-5. Philadelphia: Saunders; 2015. hlm. 179-203.

20. Minami K, Ogata J, Uezono Y. What is the main mechanism of tramadol?. Naunyn-Schmiedeberg's Arch Pharmacol. 2015;388:210-5. 